Electronic version of an article published as [European Journal of Operational Research, 2007, Vol. 176, No. 1, p. 230-239]

[DOI: http://dx.doi.org/10.1016/j.ejor.2005.06.048]

(C) [copyright Elsevier] 


\title{
Planning annualised hours with a finite set of weekly working hours and cross-trained workers ${ }^{*}$
}

\author{
Albert Corominas ${ }^{\mathrm{a}}$, Amaia Lusa ${ }^{\mathrm{a}}$ and Rafael Pastor ${ }^{\mathrm{a}}$ \\ ${ }^{a}$ Research Institute IOC, School of Industrial Engineering of Barcelona (ETSEIB), Technical University of Catalonia \\ (UPC), Av. Diagonal 647, p. 11, 08028 Barcelona, Spain
}

\begin{abstract}
Annualising working hours (i.e., the possibility of irregularly distributing the total number of working hours over a year) permits companies to adapt capacity to fluctuations in demand, thus reducing overtime, temporary workers and inventory costs. Since annual hours can lead to a worsening of the staff's working conditions, many laws and collective bargaining agreements contain constraints that affect the distribution of working time. This paper proposes a MILP model to solve an annualised working hours planning problem in which workers are considered to be cross-trained, and in which the number of weekly working hours must belong to a previously agreed finite set. A computational experiment demonstrates the effectiveness of the model.
\end{abstract}

Keywords: Human resources; Manpower planning; Annualised hours; Integer programming

*Supported by the Spanish MCyT Projects DPI2001-2176 and DPI2004-05797, co-financed by FEDER. 


\section{Introduction}

Annualising working hours $(\mathrm{AH})$ consists of hiring workers for a certain number of hours per year and distributing those hours irregularly over the year in order to accommodate fluctuations in demand. It allows for a better use of potential capacity because one can better adapt capacity to demand throughout the year. This flexibility in the use of human resources is especially useful in service organizations and in manufacturing organizations where products cannot be inventoried (e.g. are perishable).

The major advantage of annualising working hours is the reduced economic cost in comparison to other options. By using AH, costs due to a lack of capacity can be diminished and, in some cases, eliminated. Vila and Astorino (2001) give an example of a real AH scenario: an agricultural machinery manufacturer that introduced $\mathrm{AH}$ was able to reduce the overtime and the use of temporary workers by $94 \%$ and $53 \%$, respectively. A reduction in the use of temporary workers can also lead to an improvement in productivity and in the quality of the product or service. Furthermore, the service level can be improved, since demand can be covered on time.

However, AH often implies a worsening of the staff's working conditions (e.g. an irregular schedule can affect workers' private lives) and the need to solve a complicated working time planning problem.

To minimise the negative effects on the workers, the annualisation of working time has to be negotiated and may be accompanied by some sort of compensation or incentive: additional holidays, financial compensation, etc. At the same time, legal constraints or constraints drawn from a collective bargaining agreement must be respected.

The importance of annualising hours, as a source of flexibility, is increasing (Oke, 2000). The number of firms that are signing $\mathrm{AH}$ contracts is rising. However, and in spite of its growing importance, the manpower planning and scheduling problems generated by AH have not been widely studied up to now.

Corominas and Pastor, 2000 and Campbell and Diaby, 2002 propose a three-phase method in which planning, scheduling and task-assignment or allocation problems are successively solved.

This paper deals with the first phase: solving a working time planning problem. Though several models have been created to solve it, the annualisation of working hours is a subject that remains largely unexplored. Several papers discuss AH (e.g., Clutterbuck, 1982, Curran, 1992, Lynch, 1995, MacMeeking, 1995 and Mazur, 1995), but only from a qualitative point of view. Other authors emphasize that the concept of annualised hours is surprisingly absent from the literature on planning and scheduling (Hung, 1999a, Hung, 1999b, Grabot and Letouzey, 2000 and Azmat and Widmer, 2004).

Corominas and Pastor (2000) propose the use of MILP for solving an annualised working hours planning problem, but they also point out that there are many different types of problems, each of which requires a specific approach to modelling and solution.

In Corominas et al. (2004a), the characteristics of a planning problem are discussed and a classification scheme is proposed, which gives rise to thousands of different cases. Some of these types of problems are solved in other papers (see Corominas et al., 2002, Corominas et al., 2004b and Corominas et al., 2005) and the obtained solutions show that when an AH system is compared to a traditional system (regular working hours), the costs due to overtime, temporary workers, 
subcontracting, lost demand and, in some cases, inventory, are diminished. Up to now, MILP has proved to be an efficient tool for solving this kind of problem, even for large size models. However, as it is known, MILP algorithms are very sensitive to changes in the structure, in the objective function and, of course, in the size of the models. Thus, further research has still to be done to verify whether MILP is a suitable technique to solve other different cases or not.

Some of the aforementioned papers deal with manufacturing companies and the problem of planning the production and the working time of an industrial process (and not the working time of each worker). This paper solves an annualised hours planning problem based on a real case which is a chain of clothing department stores. The main contributions of this paper, compared to previous research dealing with planning working time in service companies, are: (i) overtime and temporary workers are not permitted, hence a capacity shortage is possible during certain weeks and a new utility function based on the service level is proposed; (ii) workers are considered to be cross-trained: there are different sets of worker categories who can perform different types of tasks, with different efficiencies for each type of task and each category; and (iii) the number of weekly working hours must belong to a previously agreed finite set that may be different for every worker and the holiday weeks are individualised.

The layout of the rest of this paper is as follows: Section 2 introduces the problem; Section 3 discusses the objective function; Section 4 describes the planning model; Section 5 describes the computational experiment and Section 6 presents the conclusions.

\section{Problem description}

Computing the solution of a planning problem implies determining the number of weekly working hours for each member of the staff at a service centre (assuming different types of tasks and levels of seasonal demand) and for each non-holiday week of the planning horizon (a year, for instance), with the objective of optimising a utility function. It is assumed that workers do not take their holidays at the same time, as it commonly happens in many work centres.

Numerous collective bargaining agreements do not permit overtime. In a number of other cases, tasks are too difficult to be performed by temporary workers. For the purposes of this paper, as the possibilities of overtime or hiring temporary workers are not considered, a capacity shortage is possible during certain weeks.

There are a specified number of worker categories and a predetermined number of tasks to be performed. Though a worker of a given category may be able to perform one or more types of tasks, it is possible that he or she performs them with different efficiencies. Therefore, workers in different categories may be able to meet the demand for a task, but certain categories of workers may need more time to do so than others. To model this, a relative efficiency is considered for each type of task and each category. A value of 0.9 signifies that a worker in a given category needs to work $1 / 0.9$ hours to meet a demand that a worker with a relative efficiency equal to 1 would meet in 1 hour.

The conditions to be met by the solution may stem from a legal resolution, such as the French 35 hours law (which establishes a general reduction in the total amount of annual working hours, without a reduction in wages, and permits an irregular distribution of hours over the year, provided that the rules stipulated by the law itself are observed; see MES, 2003), or from a collective bargaining agreement between management and workers. Due to the impossibility of establishing 
an exhaustive list of conditions a priori, the most common conditions are considered in order to build a basic model for the problem. Note that constraints can be added or deleted in order to adapt this model to any specific case.

One way to constrain the solutions is by specifying that the number of weekly working hours must belong to a finite set (of the types of working weeks), which may be different for each worker and for each week. In addition, the number of annual working weeks of each type must be previously established and may also be different for each worker.

The types of working weeks and the annual number of each type are established by the collective bargaining agreement. However, the planning procedure proposed here could be useful for evaluating different sets of working week types; therefore, managers and workers would be able to negotiate the most appropriate set for both. Furthermore, an extension of this paper could consider the different types of working weeks as variables in the planning model.

These conditions, added to individualised holidays, force us to consider each worker separately. Of course, this increases the size of the problem and therefore makes it difficult to solve.

In the case of the French 35 hours law, the number of weekly working hours must fall within an interval defined by a lower and an upper bound; the total number of annual working hours is upper bounded (these two conditions must be considered when creating the set of weekly working hours and establishing the number of annual weeks of each type); and the average number of weekly working hours, for any set of twelve consecutive weeks, is upper bounded (though it is assumed that this condition applies only to sets of twelve consecutive non-holiday weeks).

The characteristics of the problem are summarized below:

- The number of weekly working hours must belong to a previously agreed finite set, which may be different for each worker (for instance, working weeks of 25, 35 and 45 hours).

- The number of annual working weeks of each type is established and could be different for each worker (for instance, 11, 24 and 11 weeks of working weeks of 25, 35 and 45 hours, respectively).

- The average number of working hours for a group of 12 consecutive non-holiday weeks cannot be larger than 44 hours per week.

- Each worker has two consecutive holiday weeks in winter and four consecutive holiday weeks in summer. The holiday weeks for each worker are agreed to previously.

- There are different categories of workers and different types of tasks. Certain categories of workers can perform different types of tasks and thus have different relative efficiencies associated to them.

- Overtime is not permitted.

- Hiring temporary workers is not possible.

- A utility function has to be optimised.

These conditions are not difficult to model as linear constraints. Hence, the model can be formalised in mathematical terms. 
According to the assumptions of the problem (that overtime and temporary workers are not permitted), the cost of the staff is the same for any feasible solution. Thus, capacity has to be distributed in order to optimise the service level.

\section{Objective function}

All customers are supposed to be served when they go to the service centre: demand is met during each period, but if there is a capacity shortage, then the service level will not be as good as desirable (workers may spend too little time assisting customers). That is to say, if the required capacity (which is fixed according to foreseen demand and the optimal service level, as in a queue system) is larger than the actual capacity, then the service level worsens. Of course, to suppose that the demand is always covered would be unsustainable if the relative capacity shortages (i.e., capacity shortage related to the required capacity) were large.

Large shortages in relative capacity must be avoided: in a real case, if a capacity shortage represented a small proportion of the required capacity —although less attention would be paid to some customers - workers, with a little extra effort, could meet the demand.

The maximum relative capacity shortage, a function that is relatively simple to minimise, can be considered (the service level during the worst period is thus optimised). This function avoids large capacity shortages and, as it is known, tends to equilibrate and distribute capacity over the course of the year in a regular way.

The main inconvenience of this objective function is that once the maximum relative capacity shortage has been minimised, it is indifferent whether there is a capacity shortage in other weeks or not, given that relative capacity shortages are not higher than the maximum (Fig. 1 shows the demand, capacity and shortage profiles obtained by solving an example using this objective function). Obviously, if possible, it is more desirable to have a smaller shortage (that is to say, if it is possible to choose between different optimal solutions).

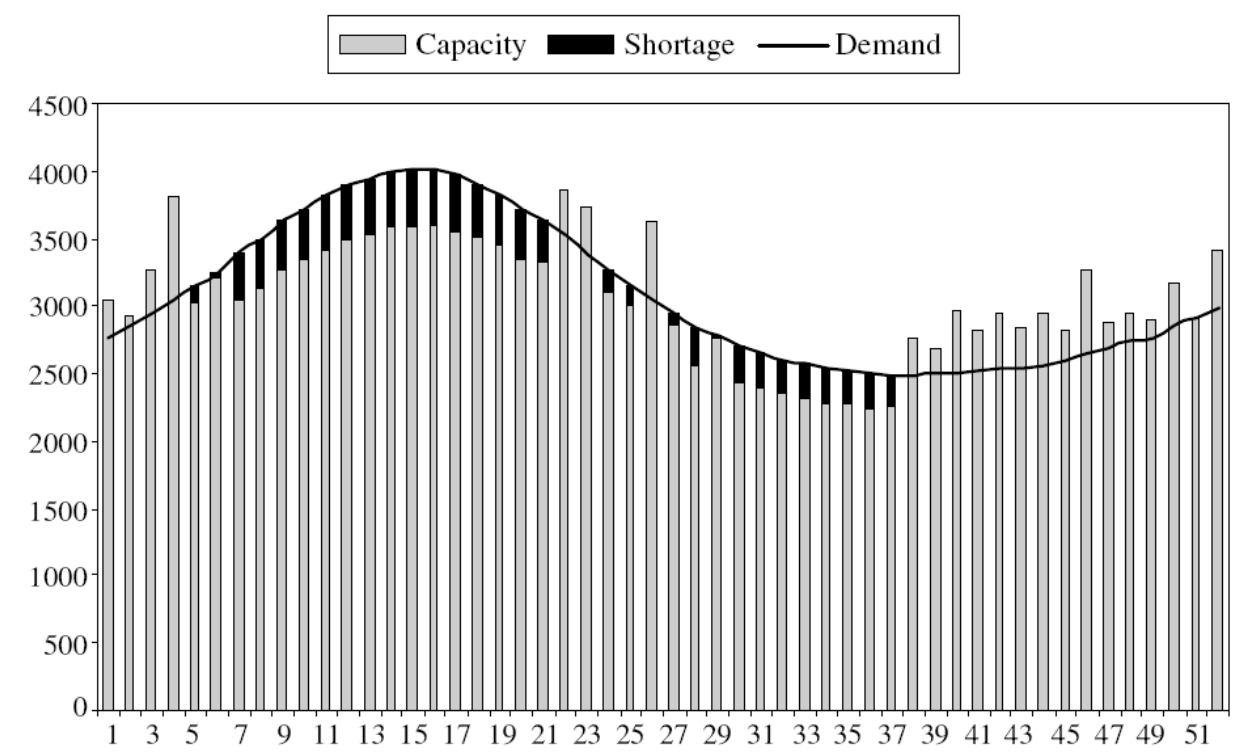

Fig. 1. Demand, capacity and shortage profiles obtained when the objective function to minimise is the maximum relative capacity shortage. 
It is possible to break the tie between optimal solutions (in order to obtain small relative capacity shortages for every week) by considering a secondary objective function (which is weighted and then added to the first one): the sum of weekly relative capacity shortages. Following this, the objective function to minimise is the weighted sum of two terms: (i) the maximum relative capacity shortage; and (ii) the sum of the weekly relative capacity shortages. Fig. 2 shows the demand, capacity and shortage profiles obtained by considering this objective function using the same data as in Fig. 1: one can see how capacity is adapted to demand, thus improving the service level.

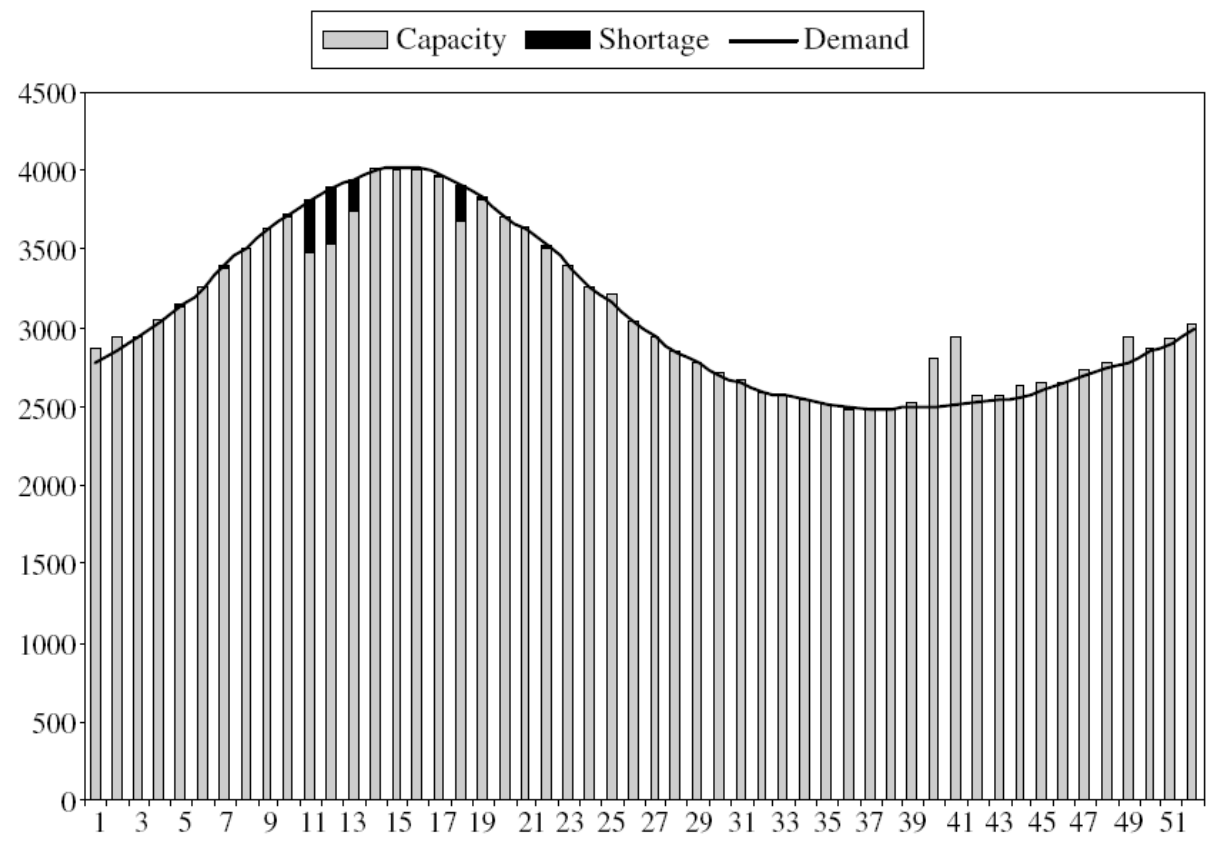

Fig. 2. Demand, capacity and shortage profiles obtained when the objective function to minimise is the weighted sum of two terms: (i) the maximum relative capacity shortage; and (ii) the sum of the weekly relative capacity shortages.

Obviously, achieving the same solution by means of regular hours and overtime instead of by annualising hours would be very expensive and, in some cases, not feasible due to legal constraints. Fig. 3 shows the overtime that would be necessary to compensate for the shortages obtained in the solution shown in Fig. 2. The overtime needed is equal to 144 hours per year per worker, which is higher than that permitted by many countries' laws (in Spain, for example, the upper bound for overtime established by law is 80 hours per year per worker). 


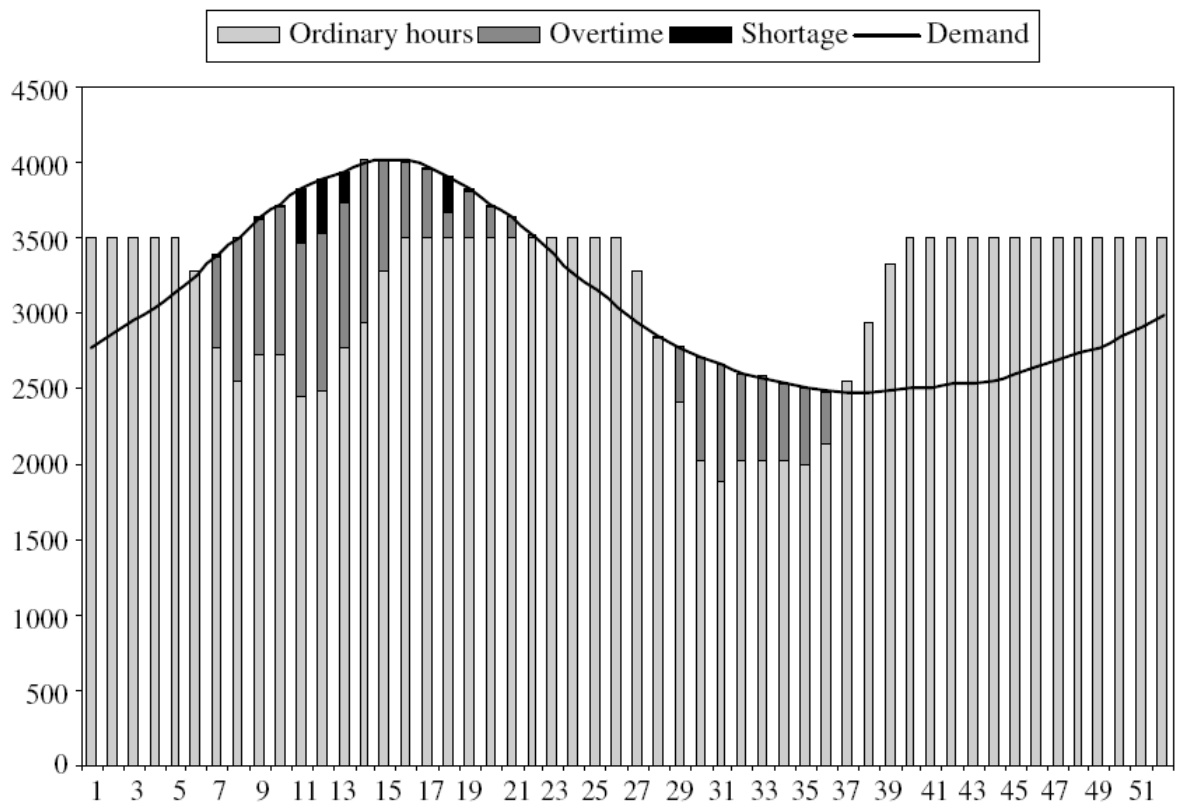

Fig. 3. Demand, capacity (ordinary hours plus overtime) and shortage profiles obtained when regular hours and overtime are used in place of annualised hours and when capacity shortages equal those obtained using annualised hours

(see Fig. 2).

\section{Model}

We make use of the following notation:

\section{Data}

$W$

set of staff members

$T$

weeks in the planning horizon (usually 52)

$S_{i}$

set of available weeks for worker $i$ (the weeks of the planning horizon excluding the worker's holiday weeks), $\forall i \in W$

$G$

set of categories of workers

$C_{i}$

category of worker $i, \forall i \in W$

$Q$

set of types of tasks 
relative efficiency associated with category $g$ workers in the accomplishment of tasks of type $q$ $(\forall g \in G ; \forall q \in Q) ; 0 \leq \tau_{g q} \leq 1$. An efficiency $\tau_{g q}=0$ indicates that category $g$ workers are not able to perform type $q$ tasks

$J_{i t}$

set of types of working weeks, expressed in working hours, that worker $i$ can perform during week $t\left(\forall i \in W, \forall t \in S_{i}\right)$

$J W_{i}$

set of types of working weeks that worker $i$ can perform over the year $\left(J W_{i}=\bigcup_{t \in S_{i}} J_{i t}\right), \forall i \in W$

$J T$

set of types of working weeks $\left(J T=\bigcup_{i \in W} J W_{i}\right)$

$H J_{k}$

number of hours corresponding to working week type $k(\forall k \in J T)$

$n_{i k}$

number of working weeks of type $k$ that must be performed by worker $i\left(\forall i \in W, \forall k \in J W_{i}\right)$

$L, h_{L}$

the average number of working hours in a group of $L$ consecutive weeks, which cannot be larger than $h_{L}$ (with $L=12$ and $h_{L}=44$ hours)

$e_{q t}$

working hours required for type $q$ tasks during week $t(\forall q \in Q ; t=1, \ldots, T)$, considering the time that a worker (with a relative efficiency of 1) would need to complete the task, and fixed according to foreseen demand and the desired service level

\section{Variables}

$x_{i k t} \in\{0,1\}$

binary variable that indicates whether worker $i$ performs a type $k$ working week during week $t$ ( $\forall i \in W, \forall t \in S_{i}, \forall k \in J_{i t}$ ); the number of variables of this type is equal to $\sum_{i \in W} \sum_{t \in S_{i}}\left|J_{i t}\right|$ $u_{g q t}$ 
non-negative real variable that indicates the number of working hours that category $g$ employees dedicate to task $q$ during week $t\left(\forall g \in G ; \forall q \in Q ; t=1, \ldots, T \mid \tau_{g q}>0\right)$. The upper bound of the number of variables is equal to $|G| \cdot|Q| \cdot T$

$d_{q t}^{-}$

non-negative real variable that indicates the capacity shortage, that is to say, the forecasted need for task $q$ that cannot be met by the staff during week $t(\forall q \in Q ; t=1, \ldots, T)$; the number of variables of this type is equal to $|Q| \cdot T$

$D$

non-negative real variable that indicates the maximum shortage, as related to the demand

Model

$[\mathrm{MIN}] Z=\alpha \cdot D+\beta \cdot \sum_{\forall q \in Q} \sum_{t=1}^{T} \frac{d_{q t}^{-}}{e_{q t}}, \quad(1)$

$D \geq \frac{d_{q t}^{-}}{e_{q t}} \quad \forall q \in Q ; t=1, \ldots, T, \quad(2)$

$\sum_{\forall k \in J_{i t}} x_{i k t}=1 \quad \forall i \in W ; \forall t \in S_{i}$, (3)

$\sum_{\left(\forall t \in S_{i}\right)\left(k \in J_{i t}\right)} x_{i k}=n_{i k} \quad \forall i \in W ; \forall k \in J W_{i},(4)$

$\sum_{(\forall g \in G)\left(\tau_{g q}>0\right)} \tau_{g p} \cdot u_{g q t}+d_{q t}^{-} \geq e_{q t} \forall q \in Q ; t=1, \ldots, T,{ }_{(5)}$

$\sum_{(\forall q \in Q)\left(\tau_{g q}>0\right)} u_{g q t}=\sum_{(\forall i \in W)\left[\left(C_{i}=g \wedge t \in S_{i}\right] \forall k \in J_{i t}\right.} \sum_{k} \cdot x_{i k t} \forall g \in G ; t=1, \ldots, T,{ }_{(6)}$

$\sum_{t=j-L+1}^{j} \sum_{\forall k \in J_{i t}} H J_{k} \cdot x_{i k t} \leq h_{L} \cdot L \quad \forall i \in W ; j=L, \ldots, T \mid[j-L+1, \ldots, j] \in S_{i}$

The objective function to minimise (1) is the weighted sum of: (i) the maximum relative capacity shortage and (ii) the sum of weekly relative capacity shortages, with $\alpha, \beta>0$; (2) expresses that $D$ is the maximum relative capacity shortage; (3) imposes, for each worker and for each available week, the assignment of one type of working week; (4) implies that each worker performs the stipulated number of working weeks of each type; (5) imposes, for each week and for each type of task, that the number of working hours performed by the staff added to the capacity shortage must be larger than or equal to the required number of working hours, according to the forecasted demand and the desired service level; (6) assigns, for each category and each week, the number of working hours of the category to the different types of tasks; and finally, (7) imposes an upper bound on the average of weekly working hours for any subset of $L$ consecutive non-holiday weeks. 


\section{Computational experiment}

A computational experiment was performed in order to evaluate the effectiveness of the model. Overall, these results can be considered very satisfactory.

The basic data used for the experiment are as follows:

- $|W|=$ staff sizes of 10, 40, 70, 100 and 250 workers.

- $T=52$ (considering 46 working weeks and 6 holiday weeks).

- The number of holiday weeks for each worker is constrained to six, distributed into two noninterrupted periods of two and four weeks, respectively. The holiday weeks are fixed at random for each worker (the two weeks of the first period in winter and the four weeks of the second in summer). Note that even though this way of generating holiday weeks might be not very realistic, it does not make solving the models any easier.

- There are three categories of workers: $50 \%$ of the workers belong to Category $1,30 \%$ belong to Category 2 and $20 \%$ belong to Category 3 .

- There are three types of tasks.

- There are three patterns of relative efficiency. Table 1, Table 2 and Table 3 show the relative efficiency values for each pattern.

Table 1.

Relative efficiency values for Pattern 1 of relative efficiency

\begin{tabular}{|l|l|l|l|}
\hline & Task1 & Task 2 & Task 3 \\
\hline Category 1 & 1 & 0.9 & 0 \\
\hline Category 2 & 0 & 1 & 0.9 \\
\hline Category 3 & 0 & 0 & 1 \\
\hline
\end{tabular}

Table 2.

Relative efficiency values for Pattern 2 of relative efficiency

\begin{tabular}{|l|l|l|l|}
\hline & Task 1 & Task 2 & Task 3 \\
\hline
\end{tabular}




\begin{tabular}{|l|l|l|l|}
\hline & Task 1 & Task 2 & Task 3 \\
\hline Category 1 & 1 & 0.9 & 0.8 \\
\hline Category 2 & 0 & 1 & 0.9 \\
\hline Category 3 & 0 & 0 & 1 \\
\hline
\end{tabular}

Table 3.

Relative efficiency values for Pattern 3 of relative efficiency

\begin{tabular}{|l|l|l|l|}
\hline & Task 1 & Task 2 & Task 3 \\
\hline Category 1 & 1 & 0 & 0 \\
\hline Category 2 & 0.9 & 1 & 0 \\
\hline Category 3 & 0.8 & 0 & 1 \\
\hline
\end{tabular}

- There are three types of working weeks for each week and each worker $\left(J_{i t}\right)$. The number of hours of each type $\left(H J_{k}\right)$ and the number of weeks of each type in a year $\left(n_{i k}\right)$ are

- Type 1: $H J_{1}=25$ hours, $n_{i 1}=15$ weeks.

- Type 2: $H J_{2}=35$ hours, $n_{i 2}=21$ weeks.

- Type 3: $H J_{3}=50$ hours, $n_{i 3}=10$ weeks.

- There are three different patterns of required capacity (in working hours) during the year. Demand Type 1 corresponds to non-seasonal capacity pattern (the required capacity is the same for all weeks in the planning horizon) with noise. Demand Type 2 corresponds to a seasonality pattern with one peak, with noise. Demand Type 3 corresponds to a seasonality pattern with two peaks, with noise. In each case, total demand is equal to total capacity (it is supposed that the number of workers was fixed according to annual demand). 
- $\alpha=0.99$ and $\beta=0.01 /(T \cdot|Q|)$. Note that the weight of each term is divided by its upper bound (1 for the first term $(D)$ and $T \cdot|Q|$ for the second term $\left(\sum_{\forall q \in Q} \sum_{t=1}^{T} \frac{d_{q t}^{-}}{e_{q t}}\right)$ ). The weight of the maximum relative capacity shortage is significantly larger than the weight that corresponds to the sum of relative capacity shortages.

For each combination of staff size $|W|$, type of demand and pattern of relative efficiency, 60 instances were generated (varying the demand noise and holiday weeks at random), giving an amount of 2700 instances.

In spite of the large size of some of the models, these were solved to optimality using the ILOG CPLEX 8.1 optimiser and a Pentium IV PC at $1.8 \mathrm{GHz}$ with $512 \mathrm{Mb}$ of RAM. The absolute and relative MIP gap tolerances were set to 0.0001 .

Computing times (expressed in seconds) and model size (which, according to the data, depends only on $W$ ) are given in Table 4. For each problem size $(|W|=10,40,70,100$ or 250 workers), one can see the minimum computing time $\left(t_{\min }\right)$, the average computing time $(\bar{t})$ and the maximum computing time $\left(t_{\max }\right)$.

Table 4.

Computing times (in seconds) by $|W|$

\begin{tabular}{|l|l|l|l|l|l|l|}
\hline$|W|$ & $\boldsymbol{t}_{\min }$ & $\bar{t}$ & $\boldsymbol{t}_{\max }$ & $\begin{array}{l}\text { Number of } \\
\text { binary } \\
\text { variables }\end{array}$ & $\begin{array}{l}\text { Number of } \\
\text { real } \\
\text { variables } \\
\text { (average) }\end{array}$ & $\begin{array}{l}\text { Number of } \\
\text { constraints } \\
\text { (average) }\end{array}$ \\
\hline 10 & 9 & 11 & 16 & 1380 & 434 & 1118 \\
\hline 40 & 11 & 13 & 64 & 5520 & 434 & 3068 \\
\hline 70 & 12 & 19 & 292 & 9660 & 434 & 5018 \\
\hline 100 & 13 & 27 & 380 & 13,800 & 434 & 6968 \\
\hline 250 & 24 & 82 & 1224 & 34,500 & 434 & 16,718 \\
\hline
\end{tabular}


As shown in Table 4, solving the model is relatively fast, even in the case of the longest solution time (1224 seconds $\approx 20$ minutes), which occurred when planning annual hours for 250 workers.

In Fig. 4, the influence of the type of demand (TD) on computing times $(t)$ can be observed. It may appear that times are shorter for Patterns 1 and 2 than for Pattern 3, but this tendency is only clear when $|W|$ is equal to 100 or 250 .

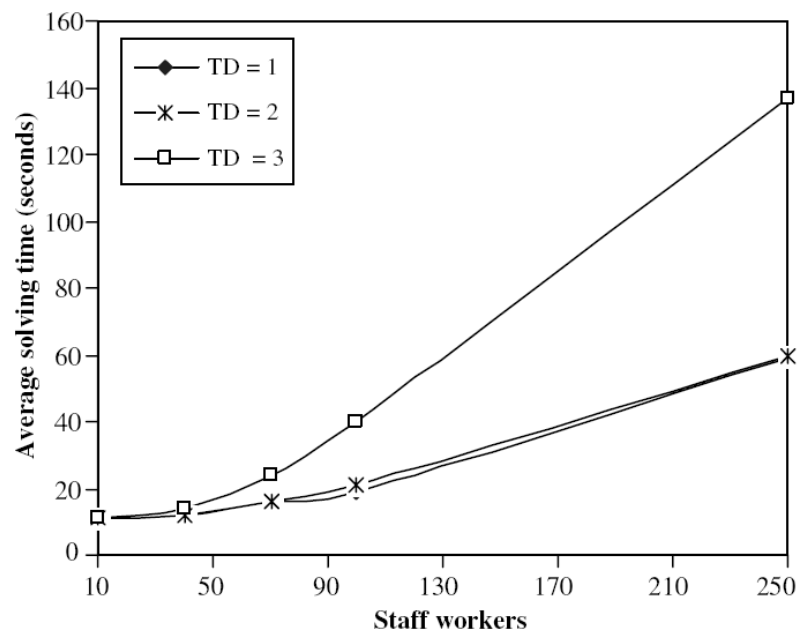

Fig. 4. Influence of type of demand (TD) on the average solution time.

Fig. 2 and Fig. 5 show how the capacity provided by the staff adapts to the demand. This is due to the flexibility provided by annualising working time. Due to the constraints, it is possible, in the same year, to have weeks with capacity surplus and others with capacity shortage (note that these appear mainly during holiday periods).

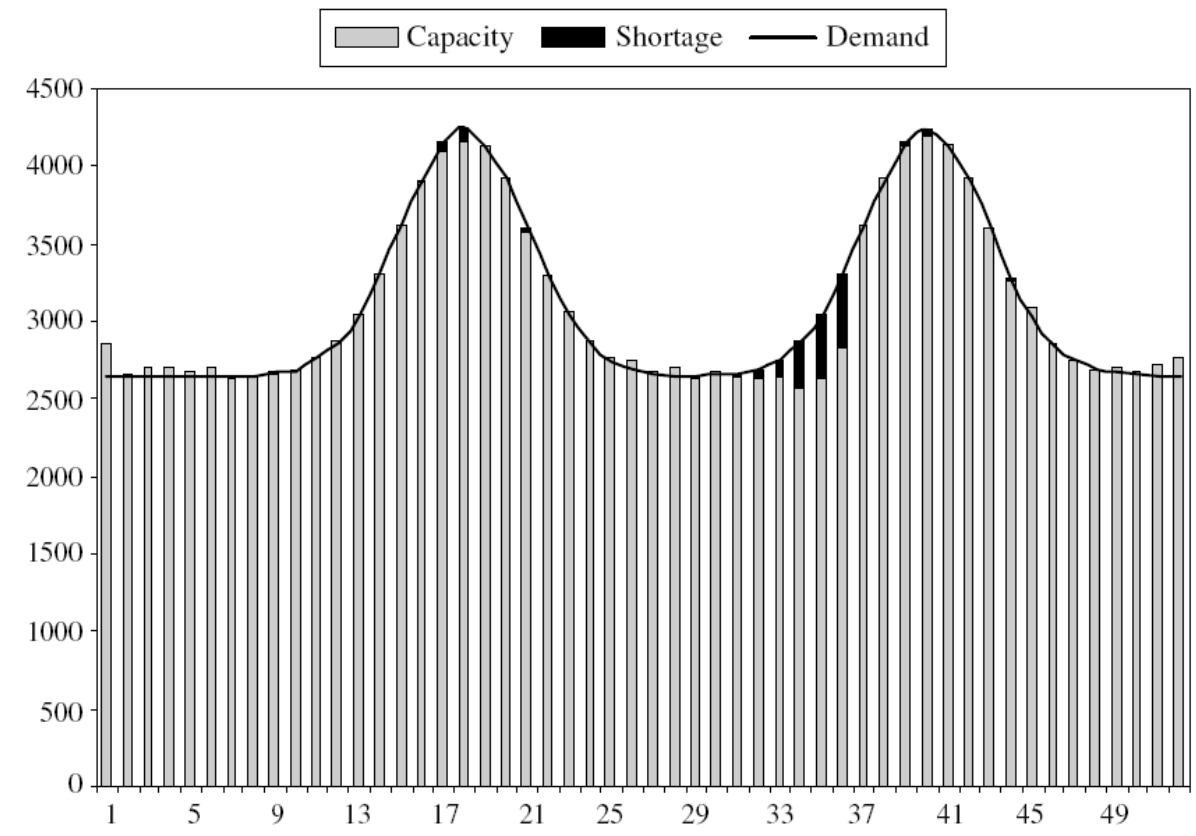

Fig. 5. Demand, capacity and shortage profiles. 


\section{Conclusions}

Annualising working hours is a good and economical way of adjusting productive capacity to seasonal demand and obtaining flexibility in the distribution of annual working hours. Annualising entails new problems to be faced, particularly those associated with planning the weekly number of working hours for an annual horizon. This paper presents a specific problem of planning working hours in the service industry. Its main characteristics are that the number of weekly working hours, for any worker and any week, must belong to a finite set; that holiday weeks are individualised; that there are different sets of workers who can perform different types of tasks (with different efficiencies); and that overtime and temporary workers are not permitted. It also presents an optimisation model for solving the problem, whose main objective is to minimise the weighted sum of two terms: (i) the maximum relative capacity shortage; and (ii) the sum of weekly relative capacity shortages.

Despite the large size of the model (especially in terms of its number of binary variables), a computational experiment has shown that MILP is an efficient tool to solve the problem in an optimal way.

The proposed planning procedure could be useful for evaluating different sets of types of working weeks; hence, managers and workers might negotiate the most appropriate set for both. Furthermore, an extension of this paper could be to include in the planning model, as variables, the types of working weeks that each worker could do in each week. 


\section{References}

Azmat and Widmer, 2004 C. Azmat and M. Widmer, A case study of single shift planning and scheduling under annualized hours: A simple three step approach, European Journal of Operational Research 153 (2004) (1), pp. 148-175.

Campbell and Diaby, 2002 G.M. Campbell and M. Diaby, Development and evaluation of an assignment heuristic for allocation cross-trained workers, European Journal of Operational Research 138 (2002), pp. 9-20.

Clutterbuck, 1982 D. Clutterbuck, After flexible hours, now it's flexiyears, International Management 37 (1982) (3), pp. 31-36.

Corominas and Pastor, 2000 Corominas, A., Pastor, R., 2000. Manpower planning and scheduling in services with seasonal demand. In: Machuca, J.A.D., Mandakovic, T. (Eds.), Proceedings of the First World Conference on Production and Operations Management, Sevilla.

Corominas et al., 2002 A. Corominas, A. Lusa and R. Pastor, Using MILP to plan annualised working hours, Journal of the Operational Research Society 53 (2002), pp. 1101-1108.

Corominas et al., 2004a A. Corominas, A. Lusa and R. Pastor, Characteristics and classification of the annualised working hours planning problems, International Journal of Services Technology and Management 5/6 (2004), pp. 435-447.

Corominas et al., 2004b A. Corominas, A. Lusa and R. Pastor, Planning annualised hours with a finite set of weekly working hours and joint holidays, Annals of Operations Research 128 (2004), pp. 217-233.

Corominas et al., 2005 Corominas, A., Lusa, A., Pastor, R., 2005. Using a MILP model to establish a framework for an annualised hours agreement. European Journal of Operational Research, in press, doi:10.1016/j.ejor.2005.04.017.

Curran, 1992 P. Curran, Annual hours brings productivity boost to Spicers, Management Services (1992) (July), pp. 32-33.

Grabot and Letouzey, 2000 B. Grabot and A. Letouzey, Short-term manpower management in manufacturing systems: New requirements and DSS prototyping, Computer Industries 3 (2000) (1), pp. 11-29.

Hung, 1999a R. Hung, A multiple-shift workforce scheduling model under annualized hours, Naval Research Logistic 46 (1999) (6), pp. 726-736.

Hung, 1999b R. Hung, Scheduling a workforce under annualized hours, International Journal of Production Research 37 (1999) (11), pp. 2419-2427.

Lynch, 1995 P. Lynch, Annual hours: An idea whose time has come, Personnel Management (1995), pp. 46-50.

MacMeeking, 1995 J. MacMeeking, Why Tesco's new composite distribution needed annual hours, International Journal Retail Distribution Management 23 (1995) (9), pp. 36-38.

Mazur, 1995 L. Mazur, Coming: The annual workweeks, Across the Board 32 (1995) (4), pp. $42-$ 45. 
MES, 2003 MES, 2003. Ministère de l'Emploi et de la Solidarité, France. $<$ www.35h.travail.gouv.fr $>(02 / 09 / 2003)$.

Oke, 2000 Oke, A., 2000. Linking human resource flexibility with manufacturing flexibility: Enablers of labour capacity flexibility in manufacturing plants. In: Machuca, J.A.D., Mandakovic, T. (Eds.), Proceedings of the First World Conference on Production and Operations Management, Sevilla.

Vila and Astorino, 2001 G.F.E. Vila and J.M. Astorino, Annualized hours as a capacity planning tool in make-to-order or assemble-to-order environment: An agricultural implements company case, Production Planning \& Control 12 (2001) (4), pp. 388-398. 